\title{
Immunotherapy as an Antifungal Strategy in Immune Compromised Hosts
}

\author{
Wilfried Posch $^{1}$ (I) $\cdot$ Doris Wilflingseder $^{1} \cdot$ Cornelia Lass-Flörl $^{1}$
}

Published online: 20 May 2020

(C) The Author(s) 2020

\begin{abstract}
Purpose of Review IFIs cause high morbidity and mortality in the immunocompromised host worldwide. Although highly effective, conventional antifungal chemotherapy faces new challenges due to late diagnosis and increasing numbers of drugresistant fungal strains. Thus, antifungal immunotherapy represents a viable treatment option, and recent advances in the field are summarized in this review.

Recent Findings Antifungal immunotherapies include application of immune cells as well as the administration of cytokines, growth factors, and antibodies. Novel strategies to treat IFIs in the immunocompromised host target intracellular signaling pathways using SMTs such as checkpoint inhibitors.

Summary Studies using cytokines or chemokines exerted a potential adjuvant role to conventional antifungal therapy, but issues on toxicity for some agents have to be resolved. Cell-based immunotherapies are very labor-intense and costly, but NK cell transfer and CAR T cell therapy provide exciting strategies to combat IFIs. Antibody-mediated protection and checkpoint inhibition are additional novel immunotherapeutic approaches.
\end{abstract}

Keywords Invasive fungal infections · Immunotherapy $\cdot$ Innate and adaptive immunity $\cdot$ Cell therapy $\cdot$ Cytokine therapy Checkpoint inhibitors

\section{Introduction}

Opportunistic fungal infections are still a major health problem in immunocompromised patients worldwide and cause an estimated 1.6 million deaths each year [1]. This reported high morbidity and mortality of fungal infections result from the lack of reliable and fast diagnostics as well as from the limited options of antifungals especially for the treatment of resistant fungi [2]. Patients with prolonged neutropenia, allogeneic hematopoietic stem cell transplant (HSCT), solid organ transplant (SOT), inherited or acquired immunodeficiencies, i.e., AIDS, or corticosteroid use are at highest risk of lifethreatening invasive fungal infections (IFIs) [3]. Although abundance of, e.g., Aspergillus conidia is high and hundreds

This article is part of the Topical Collection on Mycology

Wilfried Posch

wilfried.posch@i-med.ac.at

Institute of Hygiene and Medical Microbiology, Medical University of Innsbruck, Schöpfstrasse 41, 6020 Innsbruck, Austria are inhaled every day by each person, immunocompetent individuals are protected due to mucociliary clearance and the presence of phagocytic cells in the lungs [4, 5]. Thus, IFIs are almost exclusively observed in immunocompromised hosts. In most cases, IFIs are caused by fungi from the genera Candida, Aspergillus, Cryptococcus, or Pneumocystis, but until today, these infections are treated with antifungal drugs, since no vaccine is currently available [4]. At the moment, there are three classes of antifungal drugs available and in clinical use: azoles (e.g., fluconazole), polyenes (e.g., amphotericin B, AmB), and echinocandins (e.g., caspofungin) [6].

The incidence of mycoses is rising due to increasing use of immunomodulatory drugs to treat autoimmune diseases, cancer, and transplant recipients [4, 7]. Additionally, reports on a global emergence of antifungal resistance especially in Candida spp. and Aspergillus spp. clearly highlight the limited treatment options and the urgent need for novel strategies to improve patient prognosis with IFIs [8]. Recently, researchers could describe new classes of drugs with promising antifungal activity, but further studies are needed to exhibit the real potential of these antifungals [6]. 
Since innate and adaptive immune responses play an essential role in the protection against fungal infections, more researchers became interested in developing novel or adjunctive therapies that boost cellular and humoral functions in the host to improve patient outcome $[4,9]$. Phagocytic cells such as alveolar macrophages and neutrophils are among the first cells that encounter fungal pathogens and have also been reported to play a crucial role in the eradication of invading pathogens in the lungs [9]. These innate immune cells express a variety of extra- and intracellular pattern recognition receptors (PRRs), which recognize fungal antigens and induce proinflammatory, but also regulatory responses. Interactions of fungi with PRRs, such as C-type lectins on dendritic cells, have been characterized, and these studies revealed induction of protective adaptive immunity [10]. These qualities make innate immune cells promising therapeutic targets.

Strategies to modulate the host immune system and to strengthen antifungal immune responses include the administration of recombinant cytokines and growth factors, granulocyte- and granulocyte-macrophage colony-stimulating factors (G-CSF, GM-CSF) and antibodies (abs). Additionally, immunocompromised patients can be treated with cell therapy approaches, which include transfusion of innate and adaptive immune cells to enhance antifungal immunity. In this review, we discuss recent data on established immunotherapeutic approaches against fungal infections, but also present novel ideas using checkpoint inhibitors as antifungal therapy.

\section{Recombinant Cytokines and Immune Activating Compounds as Immune-Therapeutic Approach in Fungal Diseases}

Administration of recombinant cytokines as host-directed therapy is an important approach to strengthen immunity and fight fungal infections (Fig. 1). In addition, increased susceptibility to fungal diseases often originates from immune defects such as primary or acquired immunodeficiencies [11, 12]. To reinforce host defense mechanisms against fungi, recombinant CSFs or IFN $\gamma$ are used.

\section{Colony-Stimulating Factors}

Defects in neutrophils are a predisposing factor for opportunistic fungal infections. In order to counteract these defects, recombinant CSFs are used as an adjunct therapy to increase and activate neutrophils and enhance the host immune response to fungal pathogens (Fig. 1). Recombinant forms of GM-CSF and G-CSF that are primarily used for augmentation of neutrophils but also activation and proliferation of other myeloid cells, such as macrophages, dendritic cells (DCs), circulating monocytes, platelets, or eosinophils are FDAapproved [13-15].

In animal studies, these two FDA-approved factors illustrated promising results with respect to treatment of severe fungal infections - GM-CSF alone or in combination with recombinant IFN $\gamma$ exerted an improved fungicidal activity of innate phagocytic cells (macrophages, dendritic cells, neutrophils) [16]. Besides the fungicidal effects observed in murine models, faster renewal of neutrophils, lowering of fungal burden in the lung of immunosuppressed mice, or inhibition of macrophage suppression by the corticosteroids cortisone acetate or dexamethasone were demonstrated after GM-CSF and G-CSF administration [17, 18]. In a murine model, an improved outcome following infection with Aspergillus (A.) fumigatus was reported after treatment with G-CSF together with caspofungin or caspofungin/amphotericin B intralipid with respect to survival rates, fungal burden in organs, and reduced galactomannan serum levels [19].

Since both CSFs are approved by the FDA, G-CSF is often applied after stem cell transplantation to restore neutrophil counts and to reduce time of neutropenia in patients (reviewed in [20]) and data from animal studies using GM-CSF or GCSF seemed encouraging; studies in respect to treating IFIs in humans using CSFs appear likely.

A retrospective study by Safdar et al. investigated the use of rhGM-CSF in immunosuppressed patients with IFI [21]. The study illustrated that GM-CSF administration turned out to be safe and well tolerated, but in contrast to data in mice, where improvement of IFIs due to activation of innate phagocytes was observed, adjunct GM-CSF treatment during highdose corticosteroid therapy failed. Patients on antineoplastic therapy showed a better outcome after GM-CSF administration [15]. A prospective multicenter randomized phase IV clinical trial in 206 allogeneic stem cell patients by Wan et al. demonstrated a decrease in the combined 600-day IFIrelated mortality and yeast-disease incidence, which were administered prophylactically with either GM-CSF or G-CSF alone or in combination [15]. In contrast to yeast-disease incidence, no benefit for invasive Aspergillosis was observed in this study. Thus, contrary to murine data, both GM-CSF and G-SCF were illustrated to not being directly related to improvement in IFI-related mortality in humans. However, GM-CSF and G-CSF treatments might also support faster recovery of immune-deficient individuals during IFI, which to date has not been confirmed in larger patient cohorts. A recent study in a patient suffering from Aspergillus ventriculitis pointed to a successful recovery where GMCSF was applied in combination with voriconazole, AmB, and caspofungin [22]. In a Scedosporium apiospermum-infected patient, co-administration of the antifungal micafungin and GM-CSF resulted in a successful therapy [23]. Taken together, more in-human studies are needed for studying the effects of GM-CSF/G-SCF during fungal infections. 


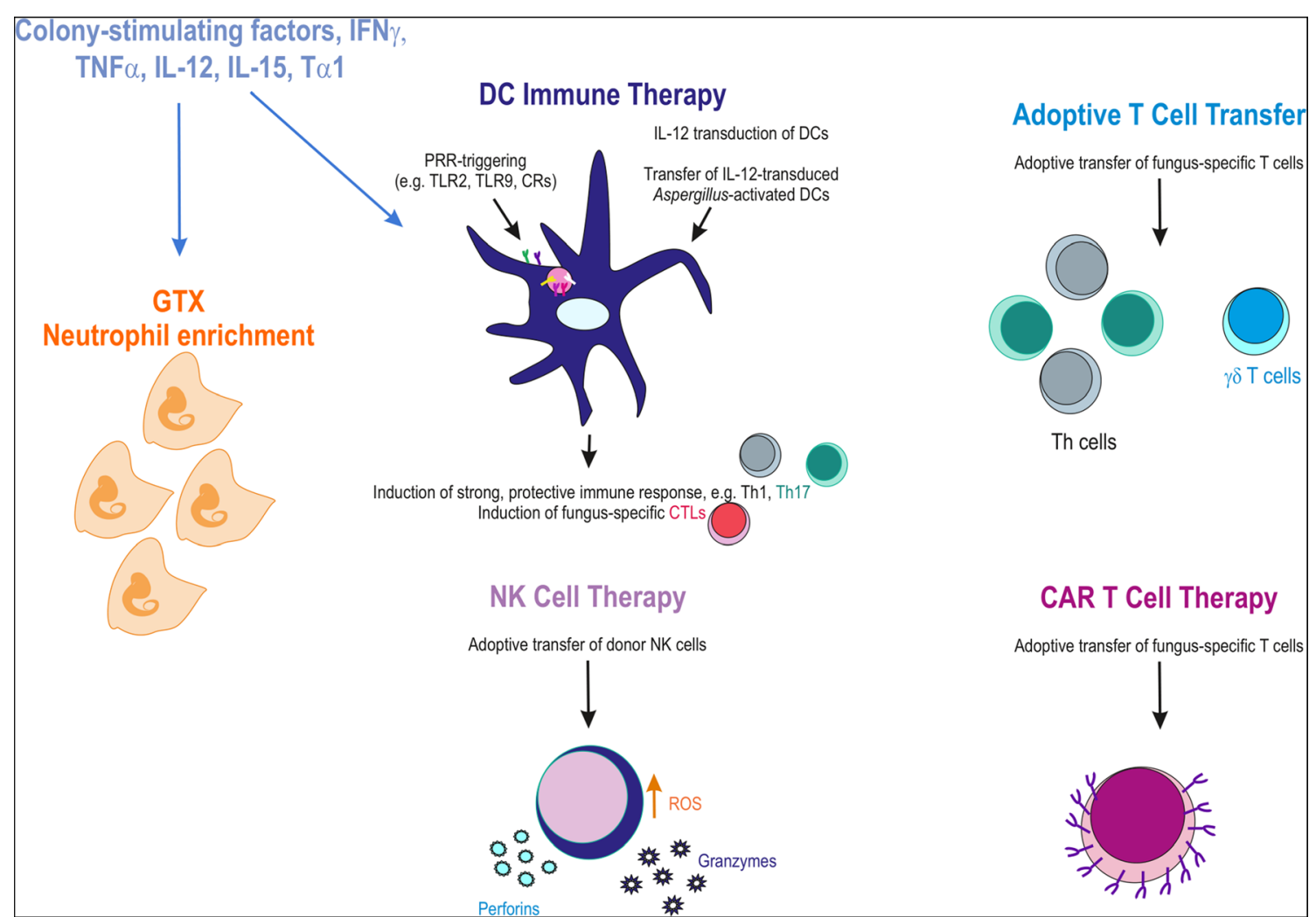

Fig. 1 Overview on humoral- and cellular-mediated immunotherapies against fungal infections. Complement receptors (CRs), cytotoxic T lymphocytes (CTLs), interferon (IFN), interleukin (IL), natural killer

Unlike G-CSF and GM-CSF, M-CSF is not FDAapproved for use in humans, and this cytokine mainly stimulates growth of macrophages (reviewed in [24]). Improvement of fungal infection was depicted in transplant mouse models treated with M-CSF [25]. In case series from 1993 by Nemunaitis et al., positive effects regarding survival of $\mathrm{M}$ CSF co-administered to conventional antifungal treatment were reported in 46 patients receiving stem cell transplantation and suffering from IFI - no follow-up study was performed, therefore this cytokine should be considered further for treatment in patients suffering from IFI after stem cell transplantation.

\section{IFNY}

Administration of the recombinant IFN $\gamma$ to patients suffering from IFI is limited to case reports and a few clinical trials [26, 27]. IFN $\gamma$ promotes polarization of naïve $\mathrm{CD} 4^{+} \mathrm{T}$ cells to $\mathrm{Th} 1$ cells, a helper cell type associated with antifungal control (Fig. 1). Beside Th1 polarization, IFN $\gamma$ exerted positive effects on fungistatic and fungicidal activities of neutrophils, and mediated $\mathrm{O}_{2}$ production from PMNs in vitro after infection with Pneumocystis carinii [28]. Furthermore, in patients suffering from IA, an increased production of proinflammatory cytokines, among those IL- $1 \beta$, TNF- $\alpha$, IL-17,
(NK), pathogen recognition receptor (PRR), reactive oxygen species (ROS), T helper cell (Th), toll-like receptor (TLR), and tumor necrosis factor (TNF)

IL-22 and higher HLA-DR, expression was observed following co-treatment with antifungals and IFN $\gamma$ [29]. All these factors are pointing to a protective role by enhancing antifungal control mechanisms, e.g., activation of Th1, Th17, Th22, improving barrier functions, or macrophage and neutrophil mobilization. A further study showed that three renal transplant patients suffering from IA were cured after combined treatment with $\mathrm{AmB}$ and IFN $\gamma$ [30]. Recombinant IFN $\gamma$ was proved safe in allogeneic stem cell transplant recipients in a single-center retrospective analysis [31]. IFN $\gamma$ was used as salvage therapy in patients with cerebral cryptococcosis and non-responding to antifungal drugs-co-administration of IFN $\gamma$ and antifungals resulted in enhanced clearance of Cryptococci [32], pointing to a supportive role by IFN $\gamma$. In vitro experiments of Scedosporium infection revealed positive effects of IFN $\gamma / \mathrm{GM}-\mathrm{CSF}$ co-application [28]—no in vivo data are available so far.

\section{TNF-a}

Neutrophils or PMNs in general are, too, activated for increased fungicidal actions by TNF- $\alpha$, the most potent innate cytokine during the defense against Aspergillus [33]. Experiments in corticosteroid-treated mice with IA revealed a decreased mortality rate if treated with TNF- $\alpha$ [34]. Another 
study in neutro- and non-neutropenic mice highlighted important protective functions of TNF- $\alpha$, since due to increased TNF- $\alpha$ levels more PMNs infiltrated the lungs and decreased mortality rates. Inhibition of TNF- $\alpha$ resulted in higher fungal burden and higher mortality [35].

In vitro analyses using human cells showed, that similar to IFN $\gamma$, TNF- $\alpha$ mediated production of oxygen radicals from PMNs, which resulted in hyphal damage during Aspergillus infection. Also, increased fungicidal effects against Candida were observed when PMNs were treated with TNF- $\alpha$ in vitro [36]. While no enhanced fungal killing was observed in alveolar macrophages, they illustrated a higher phagocytosis of Aspergillus fumigatus in the presence of TNF- $\alpha$ in vitro [37]. A major drawback on using TNF- $\alpha$ as antifungal immune therapeutic agent is its high toxicity after systemic administration [38].

\section{IL-12 and IL-15}

Not only IFN $\gamma$ and TNF- $\alpha$ but also IL-12 and IL-15 have been assessed in preclinical trials as adjunct therapy during IFI. IL-12 and IL-15 are pro-inflammatory cytokines protective during IFI due to their Th1-polarizing effects [39]. Th1 cells are essential to protect against fungal pathogens such as Candida species, Aspergillus species, or Histoplasma capsulatum. Production of IL-12 is strongly correlated with Th1 immunity against Candida (C.) albicans [40] and Cryptococcus neoformans [41] and increased the antifungal capacity of monocytes against A. fumigatus in vitro [42]. Furthermore, IL-12 was depicted to restore NK cell functions in Cryptococcus-/HIV-1-co-infected individuals [43]. In this context, IL-12 treatment reversed the defective NK cell's anticryptococcal activity and caused modulation of NK cells. However, it was also shown that in the host, IL-12 may be associated with enhanced susceptibility to fungal pathogens $[44,45]$, which makes IL-12 controversial to use as an immune therapeutic agent during fungal infections.

IL-15 was illustrated to increase the antifungal activity of granulocytes or monocytes against $C$. albicans, A. fumigatus, Fusarium spp., and Scedosporium spp. [46, 47]. IL-15 is, too, an activator of NK cells and induced IL-8 and superoxides in in vitro experiments upon infection with filamentous fungi [48]. Therefore, IL-15 exerts a potential adjuvant role to conventional antifungal therapy, but this needs further investigation.

\section{Thymosin-a-1 (Ta1)}

In kidneys of Candida-infected immune-compromised mice, lower fungal burden and higher intracellular killing of C. albicans was measured upon $\mathrm{T} \alpha 1 /$ fluconazole medication [49]. $T \alpha 1$ is a thymus-derived immune-stimulatory compound that is approved as an immune adjuvant for viral treatment in over 30 countries [50]. However, in vivo data are still missing with respect to $T \alpha 1$ in humans suffering from IFI. Thus, there is a gap of knowledge, whether this compound in combination with fluconazole is also effective in immunesuppressed humans in respect to lowering fungal burden or improving intracellular killing during Candida infection.

\section{Cell Therapy as Immune-Therapeutic Approach in Fungal Diseases}

Neutrophils, macrophages, dendritic cells (DCs), NK cells, and monocytes comprise first innate cellular defense mechanisms during fungal infections by immediately recognizing PAMPs on fungi via their abundantly expressed surface PRRs (Fig. 1) [51].

\section{Neutrophil Enrichment by Granulocyte Transfusion (GTX)}

During GTX, granulocytes containing neutrophils from a donor are transferred to a neutropenic patient, who is at risk of developing IFI [52, 53]. GTX studies in humans indicated that transfusion of neutrophils from donors stimulated with G-CSF are able to restore severely neutropenic patient's blood supply and neutrophil inflammation response, thereby rescuing the host's defenses against fungi [54]. Due to improved isolation procedures and high-quality recombinant cytokines, problems in the beginning using GTX could be overcome, which resulted in a 50-90\% response rate in IFI patients after GTX/G-CSF treatment [55]. It was further documented that prophylactic GTX might decrease the risk of fungal or bacterial infections [56]. In various case reports, GTX was demonstrated to improve survival rates in cancer patients with candidemia, to prevent recurrent fungal infections and to be effective during IA and mucormycosis [31, 54]. Yet, there are insufficient data in patients to recommend GTX during IFI [57].

\section{Dendritic Cell (DC) Immune Therapy}

During immunosuppression also DC functions may be affected, thus resulting in insufficient or inappropriate $\mathrm{T}$ cell mobilization, or cytokine production. There are several ways to restore DC functionality in immune-compromised individuals for inducing more efficient antifungal defense mechanisms. On the one hand, DCs can be activated via recombinant cytokines, but also via specific PRR activation, e.g., murine and human DCs were illustrated to up-regulate TLR2 and TLR9 upon treatment with $T \alpha 1$, they functionally matured and produced pro-inflammatory cytokines [58].

In mice, T $\alpha 1$ administration following A. fumigatus infection resulted in better survival rates, lower fungal burden, and IFN $\gamma$-producing Th1 cells on the one hand [58], and induction 
of IDO-mediated immune tolerance on the other (Fig. 1) [59]. This balanced induction of immunogenic and tolerogenic DCs by T $\alpha 1$ - or T $\alpha 1$-loaded DCs gave rise to protective immunity against $A$. fumigatus [59] and provides a promising adjunct therapeutic approach for IFI treatment, which has to be approved in humans. In a HSCT mouse model of IA, TLR9 triggering on DCs by $\mathrm{CpG}$ oligodeoxynucleotides as adjuvant together with Asp $\mathrm{f}$ 16, a major A. fumigatus allergen, resulted in protective Th1 responses [60]. Of course, all these observations from mice need approval in clinical trials in humans.

Transfusion of IL-12-transduced and Aspergillus-activated DCs and DCs pulsed ex vivo with live A. fumigatus or A. fumigatus RNA were, too, shown to mediate a protective Th1 response and protective immunity in murine models $[60$, 61].

Another novel DC-based strategy might be triggering of complement receptors (CRs) 3 and/or 4 (CR3, CR4) to mediate improved antifungal immune responses - as recently shown by us in vitro using single DC cultures or DC/T cell co-cultures of primary human origin, opsonization of viral and fungal pathogen resulted in significantly higher production of pro-inflammatory cytokines and enhanced polarization of Th1/Th17 cells [62-64]. This induced pattern is associated with protective functions during fungal infections, but needs to be approved in clinical trials.

If DCs are directly targeted ex vivo, they might mediate a strong, protective immune response as well as induction of fungus-specific, cytotoxic $\mathrm{CD}^{+} \mathrm{T}$ cells (CTLs) due to cross-presentation of fungal antigens [65]. Fungus-specific DC-based vaccination strategies are very labor-intensive and costly, because they require GMP (good manufacturing practice) guidelines, but the results so far emphasize the high potential of ex vivo-pulsed or modified DCs in therapeutic vaccination against invasive fungal infections [66]. Since most of the data were generated in animal studies or in vitro, approaches need to be tested during clinical trials in patients suffering from IFIs.

\section{NK Cell Therapy}

Human NK cells have been shown to be effective against a broad spectrum of fungi, among those A. fumigatus [67-69], C. albicans [70], Rhizopus oryzae [71], and other clinical isolates of mucormycetes [72] to name a few. Antifungal activity of NK cells is through direct mediators such as perforin and granzyme [73] and high ROS and NK cell levels correlated with improved control of IA in allo-SCT patients [74]. NK cell therapy is currently in its trial stage for cancer, but no clinical trial exists to date using NK cells for IFI treatment. However, there is a high potential of NK cell therapy as immunotherapeutic option of IFI, which has to be approved in future studies.

\section{Adoptive T Cell Transfer}

An artificial increase of fungus-specific T cells after allo-SCT might greatly support clearing of Aspergillus in immunosuppressed individuals - these are more prone to fungal infections, since even months after allo-SCT only few Aspergillus-specific $\mathrm{T}$ cells may be detected in vivo due to very slow recovery rates of adaptive immune cells [75]. A preliminary study in allo-SCT patients with uncontrolled IA demonstrated promising results, when in vitro-stimulated and selected Aspergillus-specific T cell clones were transferred to the individuals [75].

In another experimental approach, a Treg-based immunotherapy was applied [76], where co-infusion of Treg and conventional $\mathrm{T}$ cells improved immunity to fungal pathogens and prevented lethal graft-versus-host disease in the absence of immunosuppressants. However, the benefit of Treg-based immunotherapy in combination with fungus-specific, functionally active Th1 cells needs to be addressed in more detail and in bigger cohort studies.

To be clinically successful, sufficient fungus-specific and highly pure $\mathrm{CD}^{+} \mathrm{T}$ cells have to be transferred in allo-SCT patients within a very short time due to the rapid progression of IA; this is also the major obstacle with respect to adoptive T cell transfer, and many groups are working on optimizing the whole procedure. Currently, one GMP-compliant protocol is in a clinical trial (EudraCT Nr. 2013-002914-11) [77]. It is of utmost importance to control the quality of transferred $\mathrm{T}$ cells, since immunosuppressants frequently used in allo-SCT may affect them [78].

Another possibility is the application of gamma/delta $(\gamma \delta)$ $\mathrm{T}$ cells, which recognizes fundamentally different ligands from the short peptides that are seen by alpha/beta $(\alpha / \beta) \mathrm{T}$ cells in the context of MHC class I or class II molecules. These cells were also demonstrated to mediate anti-Aspergillus activity [79]. $\gamma \delta \mathrm{T}$ cells exert potent cytotoxic activity, secrete a variety of cytokines, and link innate and adaptive immunity via DCs or complement. In vivo $\gamma \delta \mathrm{T}$ cells were easily activated and expanded by stimulation with aminobisphosphonates [80]. Hence, adoptive transfer of $\gamma \delta$ $\mathrm{T}$ cells may be a promising candidate for adoptive immunotherapy to treat IFIs, since they also do not mediate alloreactivity.

\section{Chimeric Antigen Receptor (CAR) T Cell Therapy}

Currently, chimeric antigen receptor (CAR) T cell therapy is FDA-approved for several forms of aggressive, refractory non-Hodgkin lymphoma as well as for relapsed or refractory acute lymphoblastic leukemia in patients up to an age of 25 . Additionally, other trials using CAR T cell therapy are ongoing at the moment (US Food and Drug Administration FDA approves axicabtagene ciloleucel for large B cell 
lymphoma; available at www.fda.gov/drugs/ informationondrugs/approveddrugs/ucm581296.htm). This therapy is based on re-engineered $\mathrm{T}$ cells with chimeric antigen receptors. Here, the extracellular ligand recognition domain is modified to express, e.g., specificity for fungal pathogens, and connected to an intracellular signaling complex consisting of CD28, 4-1BB, or OX40 as co-stimulators and $\mathrm{CD} 3 \zeta$ to enable activation of the engineered $\mathrm{T}$ cells after antigen ligation (Fig. 1) [81, 82]. With respect to fungal infections, the single-chain variable region was exchanged by Kumaresan et al. by the C-type lectin Dectin-1, a fungusspecific receptor, to specifically target $\beta-1,3$-D-glucan on the fungal surface [82]. Cytotoxic Dectin-1-targeting CAR T cells were able to target $A$. fumigatus in vitro and in vivo in murine models, and this proof-of-principle study provides an exciting and novel immune-therapeutic approach in IFIs, but of course needs approval in clinical studies.

\section{Other Immunotherapeutic Approaches}

Administration of abs or passive immunization is a powerful tool to treat ongoing microbial infections, but since the development of modern day antibiotics and antifungals, its use has become less significant. In general, humoral immune responses were considered to play a minor role in protection against fungal infections, but recent data demonstrated the importance of antibody responses in protecting the host. Furthermore, the development of a fungal vaccine to protect individuals, who are anticipated to have severe immunosuppression in the future, has been advanced in the last years.

\section{Antibody Therapy and Fungal Vaccines}

The importance of humoral immunity in the defense of fungi has been investigated in individuals suffering from primary antibody deficiencies, e.g., X-linked agammaglobulinemia (XLA) or common variable immunodeficiency (CVID), since these patients have a higher incidence of fungal infections [83, 84]. Fungal antigens such as cell wall components (carbohydrates and glycoproteins), proteins, and other surface molecules (heat-shock proteins, HSPs) represent very promising targets for the development of protective monoclonal abs. Antibody-mediated protection can be achieved via direct and indirect mechanisms and were mostly studied in C. albicans and Cryptococcus neoformans [85]. Antibody-mediated protection can be mediated directly to inhibit biofilm formation, inhibition of polysaccharide release, interference with dimorphic changes, alterations in gene expression, iron starvation, and mimicking killer toxin using anti-idiotypic abs. The indirect group covers mechanisms such as phagocytosis, complement activation, antibody-directed cellular cytotoxicity (ADCC), phagosome activation, and modulation of inflammatory responses [85]. So far, two mAbs, 2G8 and the anti-HSP90 (efungumab, Mycograb), have been tested in immunotherapy studies. Studies using the mAb 2G8 targets laminarin, which consists of $\beta$-glucans, showed effective protection against $C$. albicans, A. fumigatus, and Cryptococcus neoformans $[86,87]$. The anti-HSP90 antibody is a single chain variable fragment ( $\mathrm{scFv}$ ) antibody and was tested in combination with lipid-associated amphotericin B (AmB) in a clinical trial. Mycograb together with $\mathrm{AmB}$ was well tolerated by patients and exhibited reduction of Candida-associated mortality and improved fungal clearance [87]. Novel approaches in antibody-mediated protection of fungal infection include radio-immunotherapy, which is a combination of radiation and immunotherapy mostly used for cancer patients. Here, antifungal abs is linked to radioisotopes to specifically deliver cytocidal radiation to target structures [88]. Studies on Cryptococcus neoformans showed that radio-immunotherapy provides a novel mechanism for the treatment of resistant fungi irrespective of the host immune status with the potential to minimize treatment time [88].

In general, vaccination is the most effective way to prevent from infection by administration of live-attenuated and inactivated pathogens or microbial protein subunits. The goal is to induce protective cellular and humoral adaptive immunity without experiencing the disease. Only a few vaccine trials were conducted against fungal infections-mostly against C. albicans, Aspergillus spp., and Cryptococcus spp. [89]. Als3p, a fungal protein, and other fungal cell wall components, were tested in combination with different adjuvants or delivery systems to boost antifungal immunity [90, 91]. Vaccination approaches were yet performed using murine models - in vivo studies investigating the recombinant Aspergillus proteins (Aspf3, Asp f9, Asp f16, Gel1, and Pep1) revealed protection in murine Aspergillosis models [91]. Furthermore, panfungal approaches have been tested using glucans and galactomannans from or heat-inactivated Saccharomyces cerevisiae as vaccines against various fungi. Data generated in these studies demonstrated protective antifungal immunity against Aspergillus spp. without the help of any additional adjuvants [91, 92]. Cenci et al. investigated the impact of live versus heat-inactivated A. fumigatus on the induction of protective antifungal immunity in a mouse model. In comparison with heat-inactivated fungi, using live A. fumigatus, higher $\mathrm{CD} 4^{+} \mathrm{T}$ cell numbers and higher IFN $\gamma$ and IL-2 levels were detected, which are associated with protection against fungal infection. [93] Vaccines against fungi are a promising tool for preventing IFIs in humans, but knowledge gaps due to missing vaccination approaches in humans exist in respect to effectivity, risks of vaccine-induced autoimmunity, or worsening the underlying disease, which need to be addressed to generate a safe antifungal vaccine. 


\section{Novel Approaches: Checkpoint Inhibitors}

Small molecular therapeutics (SMTs) that regulate, block, or inhibit intracellular signaling pathways in host cells have been widely used in cancer patients. These patient cohorts receive SMTs and immunosuppressive drugs to down-regulate host immunity and are therefore at high risk of IFIs. SMTs are widely used to treat autoimmune disease such as systemic lupus erythematosus and rheumatoid arthritis placing nonconventional populations to an elevated risk of fungal diseases [94-96]. Although the use of tyrosine-protein kinase (TK) inhibitors, non-TK inhibitors, mammalian target of rapamycin (mTOR), and autophagy regulators was associated with impaired antifungal immunity, checkpoint inhibitors could show a beneficial effect in early Aspergillus infection [97, 98]. The PD-1/PD-L1 complex acts as an immune checkpoint by dampening the immune response and promoting tolerance [99]. In early A. fumigatus infection, PD-L1 was reported to induce tolerance in DCs, which resulted in up-regulation of CTLA-4 activity and increased secretion of autoinflammatory cytokines [100]. Thus, in the future checkpoint, inhibitors may represent a promising immunotherapeutic drug, not only to treat malignant or autoinflammatory diseases but also for fungal infections.

\section{Conclusion}

IFIs are a major health problem due to growing numbers of immunosuppressive treatments, invasive medical interventions, and limitations of conventional antifungal chemotherapy together with increasing resistance of fungal strains; treatment of IFIs poses a real challenge [4, 5, 7]. Thus, immunotherapy, with and without simultaneous administration of antifungal drugs, represents an interesting approach for the treatment of IFIs. In recent years, progress has been made in the use of existing antifungal immunotherapies, and data generated in clinical research has exploited novel opportunities for improved antifungal therapy. Approaches to tackle IFIs by boosting the host's immunity include application of effector and regulatory cells as well as the administration of recombinant cytokines and growth factors, granulocyte- and granulocyte-macrophage CSF and abs. Novel strategies to treat IFIs in the immunocompromised host target intracellular signaling pathways using small molecular inhibitors such as checkpoint inhibitors. Checkpoint inhibitors have shown significant efficacy in cancer therapy and in first experiments; these molecules demonstrated their antifungal potential in early Aspergillus infection. Therefore, checkpoint inhibitors represent a promising novel immunotherapeutic option to treat IFIs, but additional studies followed by clinical trial have to be performed to assess their real antifungal activity.
Funding Information Open access funding provided by University of Innsbruck and Medical University of Innsbruck.

\section{Compliance with Ethical Standards}

Conflict of Interest Wilfried Posch and Doris Wilflingseder declare that they have no conflicts of interest. Cornelia Lass-Flörl reports grants, personal fees, and others from Gilead Sciences, grants and others from Astellas Pharma, personal fees and others from Merck Sharp and Dohme, personal fees and others from Basilea, personal fees from Angelini, personal fees and others from bioMerieux, outside the submitted work.

Human and Animal Rights and Informed Consent This article does not contain any studies with human or animal subjects performed by any of the authors.

Open Access This article is licensed under a Creative Commons Attribution 4.0 International License, which permits use, sharing, adaptation, distribution and reproduction in any medium or format, as long as you give appropriate credit to the original author(s) and the source, provide a link to the Creative Commons licence, and indicate if changes were made. The images or other third party material in this article are included in the article's Creative Commons licence, unless indicated otherwise in a credit line to the material. If material is not included in the article's Creative Commons licence and your intended use is not permitted by statutory regulation or exceeds the permitted use, you will need to obtain permission directly from the copyright holder. To view a copy of this licence, visit http://creativecommons.org/licenses/by/4.0/.

\section{References}

Papers of particular interest, published recently, have been highlighted as:

- Of importance

•• Of major importance

1. Almeida F, Rodrigues ML, Coelho C. The still underestimated problem of fungal diseases worldwide. Front Microbiol. 2019;10:214

2. McCarthy MW, Denning DW, Walsh TJ. Future research priorities in fungal resistance. J Infect Dis. 2017;216(suppl 3):S484 S92.

3. White PL, Posso RB, Barnes RA. Analytical and clinical evaluation of the PathoNostics AsperGenius assay for detection of invasive Aspergillosis and resistance to azole antifungal drugs directly from plasma samples. J Clin Microbiol. 2017;55(8):2356-66.

4. Armstrong-James D, Brown GD, Netea MG, Zelante T, Gresnigt MS, van de Veerdonk FL, et al. Immunotherapeutic approaches to treatment of fungal diseases. Lancet Infect Dis. 2017;17(12): e393-402.

5. Lauruschkat CD, Einsele H, Loeffler J. Immunomodulation as a therapy for Aspergillus infection: current status and future perspectives. J Fungi (Basel). 2018;4(4).

6. Mor V, Rella A, Farnoud AM, Singh A, Munshi M, Bryan A, et al. Identification of a new class of antifungals targeting the synthesis of fungal sphingolipids. mBio. 2015;6(3):e00647.

7. Posch W, Steger M, Wilflingseder D, Lass-Florl C. Promising immunotherapy against fungal diseases. Expert Opin Biol Ther. 2017;17(7):861-70. 
8. Hendrickson JA, Hu C, Aitken SL, Beyda N. Antifungal resistance: a concerning trend for the present and future. Curr Infect Dis Rep. 2019;21(12):47.

9. Brown GD. Innate antifungal immunity: the key role of phagocytes. Annu Rev Immunol. 2011;29:1-21.

10. Wuthrich M, Deepe GS Jr, Klein B. Adaptive immunity to fungi. Annu Rev Immunol. 2012;30:115-48.

11. Plantinga TS, Johnson MD, Scott WK, Joosten LA, van der Meer JW, Perfect JR, et al. Human genetic susceptibility to Candida infections. Med Mycol. 2012;50(8):785-94.

12. Lanternier F, Cypowyj S, Picard C, Bustamante J, Lortholary O, Casanova JL, et al. Primary immunodeficiencies underlying fungal infections. Curr Opin Pediatr. 2013;25(6):736-47.

13. Shiomi A, Usui T. Pivotal roles of GM-CSF in autoimmunity and inflammation. Mediat Inflamm. 2015;2015:568543.

14. Scriven JE, Tenforde MW, Levitz SM, Jarvis JN. Modulating host immune responses to fight invasive fungal infections. Curr Opin Microbiol. 2017;40:95-103.

15. Wan L, Zhang Y, Lai Y, Jiang M, Song Y, Zhou J, et al. Effect of granulocyte-macrophage colony-stimulating factor on prevention and treatment of invasive fungal disease in recipients of allogeneic stem-cell transplantation: a prospective multicenter randomized phase IV trial. J Clin Oncol. 2015;33(34):3999-4006.

16. Roilides E, Blake C, Holmes A, Pizzo PA, Walsh TJ. Granulocyte-macrophage colony-stimulating factor and interferon-gamma prevent dexamethasone-induced immunosuppression of antifungal monocyte activity against Aspergillus fumigatus hyphae. J Med Vet Mycol. 1996;34(1):63-9.

17. Brummer E, Maqbool A, Stevens DA. In vivo GM-CSF prevents dexamethasone suppression of killing of Aspergillus fumigatus conidia by bronchoalveolar macrophages. J Leukoc Biol. 2001;70(6):868-72.

18. Quezada G, Koshkina NV, Zweidler-McKay P, Zhou Z, Kontoyiannis DP, Kleinerman ES. Intranasal granulocytemacrophage colony-stimulating factor reduces the Aspergillus burden in an immunosuppressed murine model of pulmonary aspergillosis. Antimicrob Agents Chemother. 2008;52(2):716-8.

19. Sionov E, Mendlovic S, Segal E. Experimental systemic murine aspergillosis: treatment with polyene and caspofungin combination and G-CSF. J Antimicrob Chemother. 2005;56(3):594-7.

20. Wright CR, Ward AC, Russell AP. Granulocyte colonystimulating factor and its potential application for skeletal muscle repair and regeneration. Mediat Inflamm. 2017;2017:7517350.

21. Safdar A, Rodriguez G, Zuniga J, Al Akhrass F, Georgescu G, Pande A. Granulocyte macrophage colony-stimulating factor in 66 patients with myeloid or lymphoid neoplasms and recipients of hematopoietic stem cell transplantation with invasive fungal disease. Acta Haematol. 2013;129(1):26-34.

22. Chen TK, Groncy PK, Javahery R, Chai RY, Nagpala P, Finkelman M, et al. Successful treatment of Aspergillus ventriculitis through voriconazole adaptive pharmacotherapy, immunomodulation, and therapeutic monitoring of cerebrospinal fluid (1->3)-beta-D-glucan. Med Mycol. 2017;55(1):109-17.

23. Goldman C, Akiyama MJ, Torres J, Louie E, Meehan SA. Scedosporium apiospermum infections and the role of combination antifungal therapy and GM-CSF: a case report and review of the literature. Med Mycol Case Rep. 2016;11:40-3.

24. Hume DA, MacDonald KP. Therapeutic applications of macrophage colony-stimulating factor-1 (CSF-1) and antagonists of CSF-1 receptor (CSF-1R) signaling. Blood. 2012;119(8):1810 20.

25. Kandalla PK, Sarrazin S, Molawi K, Berruyer C, Redelberger D, Favel A, et al. M-CSF improves protection against bacterial and fungal infections after hematopoietic stem/progenitor cell transplantation. J Exp Med. 2016;213(11):2269-79.
26. Mezidi M, Belafia F, Nougaret S, Pageaux GP, Conseil M, Panaro $\mathrm{F}$, et al. Interferon gamma in association with immunosuppressive drugs withdrawal and antifungal combination as a rescue therapy for cerebral invasive Aspergillosis in a liver transplant recipient. Minerva Anestesiol. 2014;80(12):1359-60.

27. Buddingh EP, Leentjens J, van der Lugt J, Dik WA, Gresnigt MS, Netea MG, et al. Interferon-gamma immunotherapy in a patient with refractory disseminated candidiasis. Pediatr Infect Dis J. 2015;34(12):1391-4.

28. Gil-Lamaignere C, Winn RM, Simitsopoulou M, Maloukou A, Walsh TJ, Roilides E. Inteferon gamma and granulocytemacrophage colony-stimulating factor augment the antifungal activity of human polymorphonuclear leukocytes against Scedosporium spp.: comparison with Aspergillus spp. Med Mycol. 2005;43(3):253-60.

29. Delsing CE, Gresnigt MS, Leentjens J, Preijers F, Frager FA, Kox $\mathrm{M}$, et al. Interferon-gamma as adjunctive immunotherapy for invasive fungal infections: a case series. BMC Infect Dis. 2014;14: 166.

30. Armstrong-James D, Teo IA, Shrivastava S, Petrou MA, Taube D, Dorling A, et al. Exogenous interferon-gamma immunotherapy for invasive fungal infections in kidney transplant patients. Am J Transplant. 2010;10(8):1796-803.

31. Safdar A, Rodriguez G, Ohmagari N, Kontoyiannis DP, Rolston $\mathrm{KV}$, Raad II, et al. The safety of interferon-gamma-1b therapy for invasive fungal infections after hematopoietic stem cell transplantation. Cancer. 2005;103(4):731-9.

32. Jarvis JN, Meintjes G, Rebe K, Williams GN, Bicanic T, Williams A, et al. Adjunctive interferon-gamma immunotherapy for the treatment of HIV-associated cryptococcal meningitis: a randomized controlled trial. AIDS. 2012;26(9):1105-13.

33. Sainz J, Perez E, Hassan L, Moratalla A, Romero A, Collado MD, et al. Variable number of tandem repeats of TNF receptor type 2 promoter as genetic biomarker of susceptibility to develop invasive pulmonary aspergillosis. Hum Immunol. 2007;68(1):41-50.

34. Nagai H, Guo J, Choi H, Kurup V. Interferon-gamma and tumor necrosis factor-alpha protect mice from invasive aspergillosis. $\mathrm{J}$ Infect Dis. 1995;172(6):1554-60.

35. Mehrad B, Strieter RM, Standiford TJ. Role of TNF-alpha in pulmonary host defense in murine invasive aspergillosis. $\mathrm{J}$ Immunol. 1999;162(3):1633-40.

36. Roilides E, Lamaignere CG, Farmaki E. Cytokines in immunodeficient patients with invasive fungal infections: an emerging therapy. Int J Infect Dis. 2002;6(3):154-63.

37. Roilides E, Dimitriadou-Georgiadou A, Sein T, Kadiltsoglou I, Walsh TJ. Tumor necrosis factor alpha enhances antifungal activities of polymorphonuclear and mononuclear phagocytes against Aspergillus fumigatus. Infect Immun. 1998;66(12):5999-6003.

38. Roberts NJ, Zhou S, Diaz LA Jr, Holdhoff M. Systemic use of tumor necrosis factor alpha as an anticancer agent. Oncotarget. 2011;2(10):739-51.

39. Antachopoulos C, Roilides E. Cytokines and fungal infections. Br J Haematol. 2005;129(5):583-96.

40. Romani L, Puccetti P, Bistoni F. Interleukin-12 in infectious diseases. Clin Microbiol Rev. 1997;10(4):611-36.

41. Decken K, Kohler G, Palmer-Lehmann K, Wunderlin A, Mattner F, Magram J, et al. Interleukin-12 is essential for a protective Th1 response in mice infected with Cryptococcus neoformans. Infect Immun. 1998;66(10):4994-5000.

42. Antachopoulos C, Walsh TJ. Immunotherapy of Cryptococcus infections. Clin Microbiol Infect. 2012;18(2):126-33.

43. Lougaris V, Baronio M, Vitali M, Tampella G, Cattalini M, Tassone L, et al. Bruton tyrosine kinase mediates TLR9dependent human dendritic cell activation. J Allergy Clin Immunol. 2014;133(6):1644-50 e4. 
44. Romani L, Bistoni F, Mencacci A, Cenci E, Spaccapelo R, Puccetti P. IL12 in Candida albicans infections. Res Immunol. 1995;146(7-8):532-8.

45. Ruan S, McKinley L, Zheng M, Rudner X, D'Souza A, Kolls JK, et al. Interleukin-12 and host defense against murine Pneumocystis pneumonia. Infect Immun. 2008;76(5):2130-7.

46. Winn RM, Gil-Lamaignere C, Roilides E, Simitsopoulou M, Lyman CA, Maloukou A, et al. Effects of interleukin-15 on antifungal responses of human polymorphonuclear leukocytes against Fusarium spp. and Scedosporium spp. Cytokine. 2005;31(1):1-8.

47. Musso T, Calosso L, Zucca M, Millesimo M, Puliti M, BulfonePaus S, et al. Interleukin-15 activates proinflammatory and antimicrobial functions in polymorphonuclear cells. Infect Immun. 1998;66(6):2640-7.

48. Winn RM, Gil-Lamaignere C, Roilides E, Simitsopoulou M, Lyman CA, Maloukou A, et al. Selective effects of interleukin (IL)-15 on antifungal activity and IL-8 release by polymorphonuclear leukocytes in response to hyphae of Aspergillus species. J Infect Dis. 2003;188(4):585-90.

49. di Francesco P, Gaziano R, Casalinuovo IA, Belogi L, Palamara AT, Favalli C, et al. Combined effect of fluconazole and thymosin alpha 1 on systemic candidiasis in mice immunosuppressed by morphine treatments. Clin Exp Immunol. 1994;97(3):347-52.

50. Goldstein AL, Goldstein AL. From lab to bedside: emerging clinical applications of thymosin alpha 1. Expert Opin Biol Ther. 2009;9(5):593-608.

51. Lass-Florl C, Roilides E, Loffler J, Wilflingseder D, Romani L. Minireview: host defence in invasive aspergillosis. Mycoses. 2013;56(4):403-13.

52. Marr KA, Lees P, Cunningham FM. Antigen challenge increases adherence of circulating neutrophils in horses with chronic obstructive pulmonary disease. Equine Vet J. 2002;34(1):65-70.

53. Hubel K, Carter RA, Liles WC, Dale DC, Price TH, Bowden RA, et al. Granulocyte transfusion therapy for infections in candidates and recipients of HPC transplantation: a comparative analysis of feasibility and outcome for community donors versus related donors. Transfusion. 2002;42(11):1414-21.

54. Price TH, Bowden RA, Boeckh M, Bux J, Nelson K, Liles WC, et al. Phase I/II trial of neutrophil transfusions from donors stimulated with G-CSF and dexamethasone for treatment of patients with infections in hematopoietic stem cell transplantation. Blood. 2000;95(11):3302-9.

55. West KA, Gea-Banacloche J, Stroncek D, Kadri SS. Granulocyte transfusions in the management of invasive fungal infections. Br J Haematol. 2017;177(3):357-74.

56. Estcourt LJ, Stanworth S, Doree C, Blanco P, Hopewell S, Trivella M, et al. Granulocyte transfusions for preventing infections in people with neutropenia or neutrophil dysfunction. Cochrane Database Syst Rev. 2015;6:CD005341.

57. Price TH, Boeckh M, Harrison RW, McCullough J, Ness PM, Strauss RG, et al. Efficacy of transfusion with granulocytes from $\mathrm{G}-\mathrm{CSF} /$ dexamethasone-treated donors in neutropenic patients with infection. Blood. 2015;126(18):2153-61.

58. Romani L, Puccetti P. Controlling pathogenic inflammation to fungi. Expert Rev Anti-Infect Ther. 2007;5(6):1007-17.

59. Romani L, Puccetti P. Protective tolerance to fungi: the role of IL10 and tryptophan catabolism. Trends Microbiol. 2006;14(4): $183-9$.

60. Bozza S, Perruccio K, Montagnoli C, Gaziano R, Bellocchio S, Burchielli $\mathrm{E}$, et al. A dendritic cell vaccine against invasive aspergillosis in allogeneic hematopoietic transplantation. Blood. 2003;102(10):3807-14.

61. Shao C, Qu J, He L, Zhang Y, Wang J, Zhou H, et al. Dendritic cells transduced with an adenovirus vector encoding interleukin12 are a potent vaccine for invasive pulmonary aspergillosis. Genes Immun. 2005;6(2):103-14.
62. Posch W, Steger M, Knackmuss U, Blatzer M, Baldauf HM, Doppler W, et al. Complement-opsonized HIV-1 overcomes restriction in dendritic cells. PLoS Pathog. 2015;11(6):e1005005.

63. Wilflingseder D, Schroll A, Hackl H, Gallasch R, Frampton D, Lass-Florl C, et al. Immediate T-helper 17 polarization upon triggering CD11b/c on HIV-exposed dendritic cells. J Infect Dis. 2015;212(1):44-56.

64. Steger M, Bermejo-Jambrina M, Yordanov T, Wagener J, Brakhage AA, Pittl V, et al. Beta-1,3-glucan-lacking Aspergillus fumigatus mediates an efficient antifungal immune response by activating complement and dendritic cells. Virulence. 2019;10(1): 957-69.

65. Abdel-Motal UM, Dahmen J, Liu T, Ljunggren HG, Jondal M. External glycopeptide binding to MHC class-I in relation to expression of TAP transporters, beta 2-microglobulin and to $\mathrm{pH}$. Immunol Lett. 1996;54(1):31-5.

66. Roy RM, Klein BS. Dendritic cells in antifungal immunity and vaccine design. Cell Host Microbe. 2012;11(5):436-46.

67. Park SJ, Hughes MA, Burdick M, Strieter RM, Mehrad B. Early NK cell-derived IFN-\{gamma $\}$ is essential to host defense in neutropenic invasive aspergillosis. J Immunol. 2009;182(7):4306-12.

68. Bouzani M, Ok M, McCormick A, Ebel F, Kurzai O, Morton CO, et al. Human NK cells display important antifungal activity against Aspergillus fumigatus, which is directly mediated by IFN-gamma release. J Immunol. 2011;187(3):1369-76.

69. Schneider A, Blatzer M, Posch W, Schubert R, Lass-Florl C, Schmidt S, et al. Aspergillus fumigatus responds to natural killer (NK) cells with upregulation of stress related genes and inhibits the immunoregulatory function of NK cells. Oncotarget. 2016;7(44):71062-71.

70. Voigt J, Hunniger K, Bouzani M, Jacobsen ID, Barz D, Hube B, et al. Human natural killer cells acting as phagocytes against Candida albicans and mounting an inflammatory response that modulates neutrophil antifungal activity. J Infect Dis. 2014;209(4):616-26.

71. Schmidt S, Tramsen L, Perkhofer S, Lass-Florl C, Hanisch M, Roger F, et al. Rhizopus oryzae hyphae are damaged by human natural killer (NK) cells, but suppress NK cell mediated immunity. Immunobiology. 2013;218(7):939-44.

72. Schmidt S, Schneider A, Demir A, Lass-Florl C, Lehrnbecher T. Natural killer cell-mediated damage of clinical isolates of mucormycetes. Mycoses. 2016;59(1):34-8.

73. Schmidt S, Tramsen L, Hanisch M, Latge JP, Huenecke S, Koehl $\mathrm{U}$, et al. Human natural killer cells exhibit direct activity against Aspergillus fumigatus hyphae, but not against resting conidia. J Infect Dis. 2011;203(3):430-5.

74. Stuehler C, Kuenzli E, Jaeger VK, Baettig V, Ferracin F, Rajacic $\mathrm{Z}$, et al. Immune reconstitution after allogeneic hematopoietic stem cell transplantation and association with occurrence and outcome of invasive Aspergillosis. J Infect Dis. 2015;212(6):959-67.

75. Perruccio K, Tosti A, Burchielli E, Topini F, Ruggeri L, Carotti A, et al. Transferring functional immune responses to pathogens after haploidentical hematopoietic transplantation. Blood. 2005;106(13):4397-406.

76. Di Ianni M, Terenzi A, Falzetti F, Bartoli A, Di Florio S, Benedetti $\mathrm{R}$, et al. Homing and survival of thymidine kinase-transduced human T cells in NOD/SCID mice. Cancer Gene Ther. 2002;9(9):756-61.

77. Bacher P, Jochheim-Richter A, Mockel-Tenbrink N, Kniemeyer $\mathrm{O}$, Wingenfeld E, Alex R, et al. Clinical-scale isolation of the total Aspergillus fumigatus-reactive T-helper cell repertoire for adoptive transfer. Cytotherapy. 2015;17(10):1396-405.

78. Tramsen L, Schmidt S, Roeger F, Schubert R, SalzmannManrique E, Latge JP, et al. Immunosuppressive compounds exhibit particular effects on functional properties of human antiAspergillus Th1 cells. Infect Immun. 2014;82(6):2649-56. 
79. Hebart H, Bollinger C, Fisch P, Sarfati J, Meisner C, Baur M, et al. Analysis of T-cell responses to Aspergillus fumigatus antigens in healthy individuals and patients with hematologic malignancies. Blood. 2002;100(13):4521-8.

80. Kunzmann V, Kimmel B, Herrmann T, Einsele H, Wilhelm M. Inhibition of phosphoantigen-mediated gammadelta T-cell proliferation by CD4+ CD25+ FoxP3+ regulatory T cells. Immunology. 2009;126(2):256-67.

81. Srivastava S, Riddell SR. Engineering CAR-T cells: design concepts. Trends Immunol. 2015;36(8):494-502.

82. Kumaresan PR, Manuri PR, Albert ND, Maiti S, Singh H, Mi T, et al. Bioengineering $\mathrm{T}$ cells to target carbohydrate to treat opportunistic fungal infection. Proc Natl Acad Sci U S A. 2014;111(29): 10660-5.

83. Marr KA, Datta K, Pirofski LA, Barnes R. Cryptococcus gattii infection in healthy hosts: a sentinel for subclinical immunodeficiency? Clin Infect Dis. 2012;54(1):153-4.

84. Malphettes M, Gerard L, Galicier L, Boutboul D, Asli B, Szalat R, et al. Good syndrome: an adult-onset immunodeficiency remarkable for its high incidence of invasive infections and autoimmune complications. Clin Infect Dis. 2015;61(2):e13-9.

85. Casadevall A, Pirofski LA. Immunoglobulins in defense, pathogenesis, and therapy of fungal diseases. Cell Host Microbe. 2012;11(5):447-56.

86. Torosantucci A, Chiani P, Bromuro C, De Bernardis F, Palma AS, Liu Y, et al. Protection by anti-beta-glucan antibodies is associated with restricted beta-1,3 glucan binding specificity and inhibition of fungal growth and adherence. PLoS One. 2009;4(4):e5392.

87. Rachini A, Pietrella D, Lupo P, Torosantucci A, Chiani P, Bromuro $\mathrm{C}$, et al. An anti-beta-glucan monoclonal antibody inhibits growth and capsule formation of Cryptococcus neoformans in vitro and exerts therapeutic, anticryptococcal activity in vivo. Infect Immun. 2007;75(11):5085-94.

88. Nosanchuk JD, Dadachova E. Radioimmunotherapy of fungal diseases: the therapeutic potential of cytocidal radiation delivered by antibody targeting fungal cell surface antigens. Front Microbiol. 2011;2:283.

89. Nanjappa SG, Klein BS. Vaccine immunity against fungal infections. Curr Opin Immunol. 2014;28:27-33.

90. Schmidt S, Tramsen L, Perkhofer S, Lass-Florl C, Roger F, Schubert R, et al. Characterization of the cellular immune responses to Rhizopus oryzae with potential impact on immunotherapeutic strategies in hematopoietic stem cell transplantation. J Infect Dis. 2012;206(1):135-9.

91. Edwards JE Jr. Fungal cell wall vaccines: an update. J Med Microbiol. 2012;61(Pt 7):895-903.

92. Liu M, Clemons KV, Bigos M, Medovarska I, Brummer E, Stevens DA. Immune responses induced by heat killed Saccharomyces cerevisiae: a vaccine against fungal infection. Vaccine. 2011;29(9):1745-53.

93. Levitz SM. Aspergillus vaccines: hardly worth studying or worthy of hard study? Med Mycol. 2017;55(1):103-8.

94. Rip J, Van Der Ploeg EK, Hendriks RW, Corneth OBJ. The role of Bruton's tyrosine kinase in immune cell signaling and systemic autoimmunity. Crit Rev Immunol. 2018;38(1):17-62.

95. Eades CP, Armstrong-James DPH. Invasive fungal infections in the immunocompromised host: mechanistic insights in an era of changing immunotherapeutics. Med Mycol. 2019;57(Supplement_3):S307-S17.

96. Mellinghoff SC, von Bergwelt-Baildon M, Schosser HA, Cornely OA. A novel approach to candidemia? The potential role of checkpoint inhibition. Med Mycol. 2019;57(2):151-4.

97. D'Alessio FR, Tsushima K, Aggarwal NR, West EE, Willett MH, Britos MF, et al. CD4+CD25+Foxp3+ Tregs resolve experimental lung injury in mice and are present in humans with acute lung injury. J Clin Invest. 2009;119(10):2898-913.

98. Marr KA, Patterson T, Denning D. Aspergillosis. Pathogenesis, clinical manifestations, and therapy. Infect Dis Clin N Am. 2002;16(4):875-94 vi.

99. Okazaki T, Wang J. PD-1/PD-L pathway and autoimmunity. Autoimmunity. 2005;38(5):353-7.

100. Stephen-Victor E, Karnam A, Fontaine T, Beauvais A, Das M, Hegde P, et al. Aspergillus fumigatus cell wall alpha-(1,3)-glucan stimulates regulatory T-cell polarization by inducing PD-L1 expression on human dendritic cells. J Infect Dis. 2017;216(10): 1281-94.

Publisher's Note Springer Nature remains neutral with regard to jurisdictional claims in published maps and institutional affiliations. 